\title{
INTEGRASI ISLAM DAN BUDAYA NUSANTARA (TINJAUAN HISTORIS ISLAM DI NUSANTARA)
}

\section{INTEGRATION OF ISLAM AND NUSANTARA CULTURE (OVERVIEW OF HISTORICAL ISLAM IN THE NUSANTARA)}

\author{
Muhammad Ikhsan Ghofur \\ IAIN Syekh Nurjati Cirebon
}

ikhsan.ghofur@syekhnurjati.ac.id

\begin{abstract}
ABSTRAK: Islam yang berkembang baik di Nusantara maupun daerah lainnya memiliki corak yang berbeda. Hal ini dikarenakan budaya yang berkembang di masyarakat berbeda-beda satu sama lainnya. Penelitian ini berusaha untuk menganalisis tentang proses masuknya Islam di Nusantara. Cara dalam menganalisisnya adalah menggunakan metodologi penelitian pustaka (library research) dengan pendekatan sejarah yang diambil dari sumber-sumber data primer berupa buku, jurnal, dan artikel penelitian. Data-data yang diperoleh dianalisis secara deskriptif kualitatif. Adapun hasil peneltian ini adalah pertama, sebelum Islam datang, Nusantara sudah memiliki kebudayaan dan kepercayaan. Kedua, agen yang menyebarkan agama Islam berusaha mengakomodir agama dengan budaya yang ada. Ketiga, dialektika agama Islam yang teriadi di Nusantara berbeda-beda tergantung dengan budaya yang berkembang, sehingga menjadi corak dan ciri khas tersendiri bagi masing-masing wilayah
\end{abstract}

Kata Kunci: Nusantara, budaya Islam, Islam Nusantara.

ABSTRACT: Islam that developed both in the archipelago and other regions has a different style. This is because the culture that develops in the community is different. This study seeks to analyze the process of the entry of Islam in the archipelago. How to analyze it using library research method with a historical approach and analyzed descriptively. The results of this research are first, before Islam came, the archipelago already had culture and beliefs. Second, agents who spread Islam try to accommodate religion with the existing culture. Third, the dialectic of Islam that occurs in the archipelago varies depending on the developing culture, so that it becomes its own style and characteristic for each region.

Keyword: Nusantara, Islamic culture, Nusantara Islam.

\section{A. PENDAHULUAN}

Agama dan budaya merupakan satu kesatuan yang tidak dapat dipisahkan dalam masyarakat. Agama merupakan doktrin, sementara budaya menjadi sarana menerjemahkan doktrin itu sendiri. Bahkan al-Qur'an yang merupakan firman Tuhan sendiri menggunakan sarana budaya yaitu bahasa Arab. Tidak hanya penggunaan bahasa, dari segi isi pula al-Qur'an menggunakan budaya dalam mengimajinasikan surga dan neraka agar mudah dipahami oleh manusia. Hal ini diungkapkan oleh Abdurrahman Wahid, bahwa al-Qur'an sendiri sebagai sumber utama pemikiran kaum muslimin dan sendi ajaran Islam, sebenarnya berwatak lokal, penggambaran surga sebagai susu dan 
madu yang mengalir bak sungai, buah-buahan yang didambakan oleh manusia penghuni padang pasir, dan pengertian-pengertian bangsa arab akan kehidupan merupakan wahana untuk menyampaikan pesan-pesan universal yang dibawakan Islam. ${ }^{1}$ Hal ini menunjukkan bahwa al-Qur'an sendiri tetap menggunakan budaya Arab agar mudah dimengerti oleh bangsa Arab pada masa itu.

Agama Islam sendiri dalam mengimplementasikan ajarannya, memerlukan media untuk menjelaskan nilai-nilai ajaran ke dalam tatanan kehidupan manusia. Media tersebut adalah budaya yang berkembang di masyarakat. Hal ini yang kemudian menyebabkan munculnya keragamanan kebudayaan Islam. Keanekaragaman ini terjadi karena memang setiap wilayah memiliki perbedaan budaya sehingga terjadi perbedaan penafsiran dan pembumian ajaran Islam, sehingga terjadilah perpaduan ajaran Islam yang dipahami masyarakat dengan kebudayaan yang dimiliki mereka. ${ }^{2}$ Perbedaan budaya inilah yang menjadikan Islam di berbagai wilayah mengalami perbedaan. Sehingga penafsiran agama disesuaikan kebudayaan setempat agar bisa diterima dengan baik di masyarakat.

Proses perpaduan ajaran Islam dan kebudayaan juga terjadi di bumi Nusantara. Hal ini terjadi karena memang Nusantara sudah memiliki kebudayaan sebelumnya. Sehingga Islam yang masuk menyesuaikan dengan budaya yang ada di dalamnya. Selain itu pula, yang mempengaruhi corak Islam di Nusantara adalah pembawa ajaran agama itu sendiri. Karena itulah Islam harus dapat menyesuaikan dan mudah diterima di kalangan masyarakat. Penyebutan pembawa ajaran agama Islam di Nusantara juga sangat menonjolkan penyesuaian dengan warna lokal dari kesenian Islam, demikian pula wawasan lokal dari pemikiran kaum muslimin selama ini. Karena itulah penyebutan pembawa ajaran agama Islam yang muncul di Jawa adalah kyai dan pesantren, bukan syeikh dan ma' had. ${ }^{3}$ Pembawa agama yang kemudian disebut agen dari agama inilah yang menjadi penentu diterimanya Islam di Nusantara, karena mereka harus bisa menyesuaikan dengan kondisi wilayah Nusantara pada masa itu. Kondisi masyarakat yang terbuka dengan kebudayaan luar pula menjadi pendukung masuknya Islam di Nusantara. Hal ini terbukti dengan beragamnya agama yang masuk ke Nusantara yang kemudian mewarnai kebudayaan yang berlaku di masyarakat.

\footnotetext{
${ }^{1}$ Abdurrahman Wahid, Islam Kosmopolitan; Nilai-nilai Indonesia dan Transformasi Kebudayaan (Jakarta: The Wahid Institute Seeding Plural and Peaceful Islam, 2007), 342.

2 Ali Sodikin, "Dasar Teologis Integrasi Islam dan Budaya Lokal," in Islam dan Budaya Lokal, ed. oleh Ali Sodikin (Yogyakarta: Pusat Kajian Sejarah dan Budaya Islam (PKSBI), 2009), 3.

${ }^{3}$ Wahid, Islam Kosmopolitan; Nilai-nilai Indonesia dan Transformasi Kebudayaan.
} 
Dilihat dari sejarahnya, pada masa awal masuknya Islam di Nusantara banyak dipengaruhi oleh pemikiran-pemikiran tasawuf. Pemikiran sufi Ibn al-'Arabi dan Abu Hamid al-Ghazali sangat berpengaruh terhadap pengalaman-pengalaman muslim generasi pertama. Justru karena pemikiran-pemikiran tasawuf pula, penduduk Nusantara mudah memeluk agama Islam, apalagi ulama generasi pertama yang menjadi pengikut satu tarekat atau lebih. ${ }^{4}$ Hal ini diperjelas oleh Martin di mana pada abad pertama Islamisasi Asia Tenggara berbarengan dengan merebaknya tasawuf abad pertengahan dan pertumbuhan tarekat. Abu Hamid Al-Ghazali yang telah menguraikan konsep moderat tasawuf akhlaqi yang dapat diterima di kalangan para fuqaha dan Ibn Al-'Arabi yang karyanya sangat mempengaruhi ajaran hampir semua sufi yang muncul. ${ }^{5}$

Corak pemikiran tasawuf ini yang kemudian menjadikan agama Islam yang masuk pada masa itu lebih menuju ranah esensi yaitu hakikat dari agama, bukan ranah luar yang berbalut benar dan salah. Apabila Islam yang masuk menggunakan hukum yang berlaku, maka ketika masuk ke Nusantara akan langsung menyalahkan atau mengharamkan kegiatan masyarakat yang berlangsung. Hal ini dikarenakan aktivitas masyarakat Nusantara yang banyak mengkeramatkan benda atau tempat tertentu di mana praktekpraktek tersebut sangat bertentangan dengan corak Islam.

Tetapi, karena corak tasawuf yang masuk ke wilayah Nusantara maka prosesnya berbeda. Sebab tasawuf pada masa itu mengakomodir kegiatan-kegiatan masyarakat, bahkan hingga sekarang, kegiatan-kegiatan masyarakat yang bersifat sinkretis masih banyak dijumpai di wilayah Nusantara. Oleh karena itu, perlu dipahami lebih mendalam lagi tentang bagaimana sejarahnya Islam masuk di Nusantara sehingga diterima dan berkembang di masyarakat.

\section{B. METODE PENELITIAN}

Metode yang digunakan pada penelitian ini adalah metode kepustakaan yang mana peneliti mengumpulkan beberapa referensi di mana objek penelitian digali lewat beragam informasi kepustakaan untuk dianalisis. ${ }^{6}$ Pendekatan yang digunakan dalam penelitian ini adalah pendekatan historis dan antropologis. Sedangkan teknik analisis data

\footnotetext{
${ }^{4}$ Sri et.al Mulyati, Mengenal dan Memahami Tarekat-Tarekat Muktabarah di Indonesia (Jakarta: Kencana Prenada Media Group, 2011), 8.

${ }^{5}$ Martin Van Bruinessen, Kitab Kuning, Pesantren, dan Tarekat (Yogyakarta: Gading Publishing, 2012), 226.

${ }^{6}$ Mestika Zed, Metode Penelitian Kepustakaan (Jakarta: Yayasan Obor Indonesia, 2008), 89.
} 
menggunakan analisis deskriptif ${ }^{7}$ yang mana semua data dianalisis menggunakan teori akulturasi dan kemudian dijelaskan bentuk dari akulturasi tersebut. ${ }^{8}$

\section{HASIL DAN PEMBAHASAN}

\section{Nusantara Pra Islam}

Sebelum Islam masuk, masyarakat Nusantara sudah memiliki kebudayaan dan kepercayaan yang dianut. Bahkan kepercayaan itu hingga Islam ada di wilayah Nusantara tetap ada di masyarakat. Kepercayaan ini disebut dengan kepercayaan animisme dan dinamisme. Menurut Koentjaraningrat, animisme adalah kepercayaan bahwa dunia ini dipenuhi ruh-ruh atau jiwa-jiwa, yang tidak tertangkap oleh indera dan bertempat di tempat tinggal manusia. Ia dapat berbuat apa saja yang tidak dapat diperbuat oleh manusia. Ruh-ruh itu mendapat tempat yang penting dalam hidup manusia dan menjadi objek penghormatan dan penyembahan, yang disertai dengan berbagai upacara berupa doa (mantera), sajian atau kurban. ${ }^{9}$ Kepercayaan manusia akan ruh-ruh atau jiwa-jiwa masih berjalan hingga sekarang. Ruh tersebut merupakan hal yang harus dijaga agar terjadi keseimbangan di dalam dunia. Karena ruh tersebut dipercayai akan mengganggu manusia bila mereka merasa terganggu. Ruh tersebut dihormati agar keselarasan alam tetap terjaga, karena ia juga makhluk di alam ini tetapi di dalam dimensi lain.

Kepercayaan animisme mempercayai bahwa setiap benda di bumi ini mempunyai jiwa yang mesti dihormati agar tidak mengganggu manusia. Sedangkan dinamisme adalah pemujaan terhadap roh nenek moyang yang telah meninggal dan menetap dalam tempat-tempat tertentu. ${ }^{10}$ Kepercayaan-kepercayaan seperti ini masih sangat terlihat jelas hingga sekarang di masyarakat. Hal ini dapat dilihat dari adanya beberapa golongan masyarakat yang memiliki benda pusaka yang kemudian disimpan dan dirawat dikediamannya. Kepercayaan ini tentunya memberikan dampak positif kepada alam, karena dengan kepercayaan tersebut akan menjadikan masyarakat lebih menjaga keseimbangan alam.

\footnotetext{
${ }^{7}$ Lexy J Moleong, Metode Penelitian Kualitatif (Bandung: PT Remaja Rosdakarya, 2011), 257.

${ }^{8}$ Koentjaraningrat, Pengantar Ilmu Antropologi (Jakarta: Rineka Cipta, 2009), 262.

${ }^{9}$ Dr Hidayat, Akulturasi Islam dan budaya Melayu: studi tentang ritus siklus kehidupan orang Melayu di Pelalawan, Provinsi Riau (Badan Litbang dan Diklat, Departemen Agama RI, 2009), 99.

${ }^{10}$ Ahmad Afandi, "Kepercayaan Animisme-Dinamisme Serta Adaptasi Kebudayaan Hindu-Budha Dengan Kebudayaan Asli Di Pulau Lombok-NTB," Historis: Jurnal Kajian, Penelitian dan Pengembangan Pendidikan Sejarah 1, no. 1 (2018): 2.
} 
Selain kepercayaan animisme dan dinamisme, juga ada agama Hindu dan Budha. Adanya agama Hindu dan Budha dilihat dari sejarahnya melalui adanya kerajaankerajaan besar di Nusantara. Kerajaan Hindu yaitu kerajaan Majapahit sedangakan kerajaan Budha adalah kerajaan Sriwijaya. ${ }^{11}$ Selain itu adanya candi-candi di Nusantara menandakan bahwa agama Hindu dan Budha juga memasuki wilayah Nusantara. Agama Hindu dan Budha tidak merubah kepercayaan masyarakat, bahkan hampir memiliki kesamaan, hanya saja pemujaannya dialihkan kepada dewa-dewa. Hal ini yang kemudian menjadikan agama Hindu dan Budha tumbuh subur di wilayah Nusantara.

\section{Agen-Agen Islamisasi di Nusantara}

Proses Islamisasi di wilayah Nusantara tidak lepas dari peran para pemuka agama yang menyebarkan agama Islam. Hal ini dikarenakan strategi yang digunakan dalam menyampaikan agama menggunakan budaya dan bisa diterima oleh masyarakat. Di wilayah Sumatera, terutama daerah Pasai, strategi yang digunakan adalah bidang politik. Tokoh yang melakukan Islamisasi di wilayah aceh adalah Syekh Ismail yang kemudian mengislamkan Meurah Silu penguasa Pasai. ${ }^{12}$ Selain dalam dunia politik, dalam bidang budaya khususnya hukum adat juga dilakukan meskipun prosesnya cukup lama dan banyak penolakan. Tokohnya adalah Syekh Akhmat Khatib yang menolak harta pusaka yang kemudian diklasifikasi oleh Syekh Abdul Karim Amrullah menjadi harta pusaka dan harta pencarian. ${ }^{13}$

Di wilayah Jawa juga metode yang dilakukan bermacam-macam. Ranah politik juga dilakukan, salah satunya adalah adanya kerajaan Demak dengan rajanya Raden Fatah. Dengan raja yang beragama Islam tentunya rakyat akan ikut beragama Islam. Di bidang budaya, tokoh yang melakukan adalah para songo terutama Sunan Bonang, Sunan Kalijaga, dan Sunan Kudus yang mampu meramu agama dalam budaya

\footnotetext{
${ }^{11}$ Hidayat, Akulturasi Islam dan budaya Melayu: studi tentang ritus siklus kehidupan orang Melayu di Pelalawan, Provinsi Riau.

${ }^{12}$ Aji Setiawan ST, "Menelisik Kajian Islam dan Jejaring Ulama Nusantara," The International Journal of Pegon: Islam Nusantara civilization 4, no. 02 (2020): 31.

${ }^{13}$ Muhammad Ikhsan Ghofur, "AKULTURASI ADAT DAN HUKUM ISLAM TERKAIT HARTA WARISAN SUKU MINANGKABAU," Empower: Jurnal Pengembangan Masyarakat Islam 2, no. 2 (2017): 59.
} 
setempat. ${ }^{14}$ Hasil ramuan tersebut diantaranya upacara keagamaan, pertunjukan wayang, langgam jawa, dan arsiteksur perpaduan antara hindu budha dan Islam.

Di wilayah Lombok juga terjadi Islamisasi melalui budaya. Tokohnya adalah Sunan Prapen dengan putranya yaitu Nurcahya dan Nursada yang melalukan penyebaran agama Islam melalui budaya. ${ }^{15}$ Islam tersebut sekarang dikenal Islam Wetu Telu. Dalam prakteknya warna agama bercampur dengan adat walaupun adat sendiri tidak sejalan dengan agama. ${ }^{16}$ Walaupun sedikit berbeda dalam prakteknya, namun Islam tetap diterima di masyarakat Lombok dan memberikan corak tersendiri terhadap keberagaman Islam di Nusantara.

Dilihat dari agen-agen yang melakukan penyebaran agama Islam di beberapa wilayah nusantara menandakan bahwa mereka mengakomodir budaya setempat. Budaya yang berbeda-beda menjadikan metode yang digunakan berbeda pula, sehingga akan membentuk ciri khas masing-masing antar wilayah. Tentunya dengan menyesuaikan bentuk budaya dan tidak memaksakan agar sesuai dengan budaya di mana agama Islam berasal.

\section{Dialektika Islam dengan Kebudayaan Nusantara}

Budaya yang berkembang di Indonesia merupakan akulturasi dari berbagai macam budaya yang sangat kompleks. Hal ini dikarenakan Indonesia merupakan jalur lalu lintas perdagangan dan tempat persinggahan para penjajah. Sehingga banyak masyarakat keluar masuk wilyah Indonesia dan memberikan pengaruh kepada budaya yang ada. Agama Islam pun tak luput memberikan pengaruh kepada Indonesia melalui agen-agennya. Dalam tahapannya, proses akulturasi budaya terjadi secara damai. Satu sisi, adakalanya budaya Islam yang dominan, tetapi disisi lain, budaya asli mendominasi pencampuran budaya tersebut. ${ }^{17}$ Proses saling dominan ini yang kemudian memberikan corak yang berbeda-beda dalam agama Islam yang dianut di berbagai wilayah. Hal ini mengakibatkan pemahaman agama di wilayah Sumatera

\footnotetext{
${ }^{14}$ Achmad Syafrizal, “Sejarah Islam Nusantara," Islamuna: Jurnal Studi Islam 2, no. 2 (2015): 244-49.

15 Zaki Yamani Athhar, "Kearifan Lokal dalam Ajaran Islam Wetu Telu di Lombok," Ulumuna 9, no. 1 (2005): 75.

${ }^{16}$ Muhammad Harfin Zuhdi, "Islam Wetu Telu [Dialektika Hukum Islam dengan Tradisi Lokal]," Istinbath: Jurnal Hukum Islam IAIN Mataram 13, no. 2 (2014): 163.

${ }^{17}$ Abdul Karim, Islam Nusantara (Yogyakarta: Pustaka Book Publisher, 2007), 143.
} 
dan Jawa bisa berbeda tergantung dari agen yang membawa dan mengakomodir budaya setempat.

Setelah runtuhnya Majapahit $1520 \mathrm{M}$; di daerah pesisir proses Islamisasi berjalan intensif hingga akhirnya berdirilah kerajaan-kerajaan Islam seperti Demak, Banten dan Cirebon. Namun dalam segi pemahaman akidah Islam, tidak serta merta mantap dan melenyapkan alam pikiran filsafat lama, seperti Hindu dan Budha. Mereka memang mengucapkan kalimat syahadat, akan tetapi kenangan dan praktik kepada kepercayaan kepada Bata Guru, Batara Wisnu, dan lainnya masih tetap hidup. Di sinilah muncul kecenderungan sinkretisme. Dengan demikian, maka Islam yang berkembang di pedalaman Jawa berbeda dengan Islam yang berkembang di pesisir adalah Islam yang mobilitas sosialnya tinggi dan mengikuti perkembangan dunia Islam. Setelah kerajaan Majapahit runtuh, maka muncul penggantinya di daerah pedalaman, muncullah kerajaan Mataram Islam tahun 1575 M. ${ }^{18}$ Kerajaan Mataram Islam ini pula yang memberikan corak Islam di pedalaman. Hal ini dikarenakan kerajaan menjadi pusat kebudayaan dan memberikan pengaruh kepada masyarakat. Segala kebijakan raja akan menjadi aturan yang harus ditaati oleh masyarakat.

Selain itu, kehadiran Islam di Indonesia juga tak lepas dari peran para sufi. Hal ini menyebabkan Islam pada masa awal banyak berkompromi dengan budaya lokal. Pertemuan Islam dengan budaya lokal sering disalahpahami sebagai penyebab kurang murninya Islam di Indonesia. Namun, perlu ditegaskan bahwa tasawuf yang berkembang di Indonesia adalah tasawuf yang berpadu dengan syariat secara seimbang. ${ }^{19}$ Jadi walaupun terlihat berbeda dari asal agama ini berada, namun pada hakikatnya agama yang diajarkan adalah sama. Tetapi prakteknya di Nusantara lebih menyesuakan dengan kondisi kebudayaan setempat. Hal yang menyebabkan tasawuf mudah diterima di masyarakat Indonesia terkait juga dengan kepercayaan lama. Masyarakat Indonesia yang percaya mistis-mistis menyebabkan mereka menyukai hal-hal yang berbau sakti.

Selain tasawuf, dalam bidang fikih juga berperan dalam masuknya Islam di Nusantara. Walaupun terdapat konflik di dalamnya, namun penerapannya bisa

\footnotetext{
${ }^{18}$ M Arsad AT, "Kajian Kritis Tentang Akulturasi Islam dan Budaya Lokal," Lentera Pendidikan: Jurnal Ilmu Tarbiyah dan Keguruan 15, no. 2 (2012): 213.

${ }^{19}$ H S Mastuki, "Islam, Budaya Indonesia, Dan Posisi Kajian Islam Di Perguruan Tinggi Islam," Khazanah: Jurnal Studi Islam Dan Humaniora 12, no. 1 (2017): 21.
} 
berkolaborasi dengan budaya setempat. Salah satu perpaduan antara fikih dengan budaya adalah tentang harta pusaka suku Minangkabau yang memisahkan pembagian harta warisan berdasarkan adat dan hukum Islam. ${ }^{20}$ Di bidang kesenian, berupa wayang dengan penokohan punakawan. Di bidang arsitektur, berupa masjid Kudus dan adanya gambar kura-kura di masjid Demak. Di upacara tradisional, berupa upacara gerebek. Selain itu, dalam sistem kalender juga terdapat perpaduan antara kalender saka dengan kalender hijriah yang menjadi kalender Jawa. ${ }^{21}$ Perpaduan agama dan budaya yang terjadi di segala aspek ini menandakan bahwa metode yang diterapkan menyesuaikan dengan adat dan budaya setempat. Dengan penyesuaian ini menjadi wajar bahwa terdapat perbedaan pandangan dalam berbagai wilayah, sehingga justru menambah khazanah Islam di Nusantara.

Diterimannya agama Islam di semua bidang karena memang masyarakat yang sangat terbuka dengan budaya dan agama dari luar. Masyarakat memiliki sifat menerima, bisa berkompromi dengan hal-hal yang tidak sesuai, dan lebih menjaga kerukunan daripada perselisihan. Bagi masyarakat nusantara khususnya Jawa, keselarasan atau harmoni antara jagad gede (makrokosmos) dan jagad kecil (mikrokosmos) sangat menonjol sehingga diupayakan untuk selalu dijaga dengan baik. Upaya ini menemukan bentuknya dalam ungkapan selamet. Orang Jawa memiliki konsep tentang "rasa" yang sangat baik dalam menghadapi benturan-benturan. ${ }^{22}$

Edi Susanto dan Karimullah menegaskan bahwa pertama Islam datang mempertimbahkan tradisi, tradisi yang berlawanan dicoba untuk diapresiasi yang kemudian dijadikan sarana pengembangan Islam. Kedua, Islam tidak mengusik agama dan kepercayaan apapun sehingga hidup berdampingan. Ketiga, Islam mendinamisasi tradisi sehingga diterima sebagai tradisi dan agama. Keempat, Islam menjadi agama yang mentradisi, sehingga masyarakat hidup dalam tradisi Islam. ${ }^{23}$ Hal ini menunjukan bahwa Islam hadir di Nusantara menyatu dalam tradisi yang ada,

\footnotetext{
${ }^{20}$ Ghofur, "AKULTURASI ADAT DAN HUKUM ISLAM TERKAIT HARTA WARISAN SUKU MINANGKABAU."

${ }^{21}$ Maharsi, "Pola-Pola Perpaduan Islam dan Budaya Nusantara," in Islam dan Budaya Lokal, ed. oleh Ali Sodikin (Yogyakarta: Pusat Kajian Sejarah dan Budaya Islam (PKSBI), 2009), 30-39.

${ }^{22}$ Mudhofir Abdullah, "Pribumisasi Islam dalam Konteks Budaya Jawa dan Integrasi Bangsa," Jurnal IndoIslamika 4, no. 1 (2014): 77.

${ }^{23}$ Edi Susanto dan Karimullah Karimullah, "Islam Nusantara: Islam Khas dan Akomodatif terhadap Budaya Lokal," Al-Ulum 16, no. 1 (2016): 70.
} 
sehingga kegiatan-kegiatan yang berlangsung di masyarakat tetap kembali kepada Sang Pencipta, walaupun pada prakteknya menggunakan sarana. Selain itu pula, adanya peninggalan agama Hindu Budha yang tetap terjaga menunjukkan bahwa agama Islam dengan agama lain berdampingan dan saling menjaga menjalin keharmonisan.

\section{SIMPULAN}

Berdasarkan pembahasan tentang tentang integrasi Islam dan budaya di Nusantara dapat disimpulkan bahwa Nusantara sebelum Islam ada sudah memiliki agama dan kebudayaan. Mulai dari kepercayaan animisme dan dinamisme hingga agama hindu dan budha. Hal ini menunjukan bahwa sebelum Islam datang, kondisi Nusantara sudah memiliki budaya dan agama. Bentuk-bentuk dari kebudayaan yang ada pada masyarakat Nusantara masih bisa dirasakan hingga sekarang. Bentuk-bentuknya berupa sebaran candi di Nusantara yang cukup banyak. Hal ini dikarenakan agama mendapat dukungan pada aspek politik yaitu kerajaan.

Selanjutnya, agen-agen Islamisasi di Nusantara menggunakan cara akomodir budaya dan agama dalam menyebarkan agama Islam. Dari cara inilah yang kemudian menjadikan praktek kehidupan dalam beragama berbeda-beda. Hal ini yang kemudian menjadi ciri khas masing-masing daerah dalam beragama. Dialektika yang terjadi antara agama dan budaya setiap daerah berbeda-beda. Ada yang corak keislamannya yang lebih dominan, adapula corak budaya yang lebih dominan. Hal ini dipengaruhi oleh berbagai hal, diantaranya adalah agen pembawa yang mengakomodir agama dan budaya, kekuatan politik atau kerajaan pada saat itu, dan budaya serta pemahanan yang dimiliki masyarakat. Diterimanya Islam oleh masyarakat dikarenakan masyarakat Nusantara yang terbuka dengan budaya baru. Dengan sikap yang demikian, dan agen yang mampu mengakomodir budaya menjadikan agama Islam diterima dan menyesuaikan dengan kebudayaan setempat.

\section{DAFTAR PUSTAKA}

Abdullah, Mudhofir. "Pribumisasi Islam dalam Konteks Budaya Jawa dan Integrasi Bangsa.” Jurnal Indo-Islamika 4, no. 1 (2014): 67-90.

Afandi, Ahmad. "Kepercayaan Animisme-Dinamisme Serta Adaptasi Kebudayaan Hindu-Budha Dengan Kebudayaan Asli Di Pulau Lombok-NTB.” Historis: Jurnal 
Kajian, Penelitian dan Pengembangan Pendidikan Sejarah 1, no. 1 (2018): 1-9.

AT, M Arsad. "Kajian Kritis Tentang Akulturasi Islam dan Budaya Lokal." Lentera Pendidikan: Jurnal Ilmu Tarbiyah dan Keguruan 15, no. 2 (2012): 211-20.

Athhar, Zaki Yamani. "Kearifan Lokal dalam Ajaran Islam Wetu Telu di Lombok." Ulumuna 9, no. 1 (2005): 70-89.

Bruinessen, Martin Van. Kitab Kuning, Pesantren, dan Tarekat. Yogyakarta: Gading Publishing, 2012.

Ghofur, Muhammad Ikhsan. “AKULTURASI ADAT DAN HUKUM ISLAM TERKAIT HARTA WARISAN SUKU MINANGKABAU.” Empower: Jurnal Pengembangan Masyarakat Islam 2, no. 2 (2017): 53-66.

Hidayat, Dr. Akulturasi Islam dan budaya Melayu: studi tentang ritus siklus kehidupan orang Melayu di Pelalawan, Provinsi Riau. Badan Litbang dan Diklat, Departemen Agama RI, 2009.

Karim, Abdul. Islam Nusantara. Yogyakarta: Pustaka Book Publisher, 2007.

Koentjaraningrat. Pengantar Ilmu Antropologi. Jakarta: Rineka Cipta, 2009.

Maharsi. "Pola-Pola Perpaduan Islam dan Budaya Nusantara." In Islam dan Budaya Lokal, diedit oleh Ali Sodikin. Yogyakarta: Pusat Kajian Sejarah dan Budaya Islam (PKSBI), 2009.

Mastuki, H S. "Islam, Budaya Indonesia, Dan Posisi Kajian Islam Di Perguruan Tinggi Islam.” Khazanah: Jurnal Studi Islam Dan Humaniora 12, no. 1 (2017).

Moleong, Lexy J. Metode Penelitian Kualitatif. Bandung: PT Remaja Rosdakarya, 2011.

Mulyati, Sri et.al. Mengenal dan Memahami Tarekat-Tarekat Muktabarah di Indonesia. Jakarta: Kencana Prenada Media Group, 2011.

Sodikin, Ali. "Dasar Teologis Integrasi Islam dan Budaya Lokal." In Islam dan Budaya Lokal, diedit oleh Ali Sodikin. Yogyakarta: Pusat Kajian Sejarah dan Budaya Islam (PKSBI), 2009.

ST, Aji Setiawan. "Menelisik Kajian Islam dan Jejaring Ulama Nusantara." The International Journal of Pegon: Islam Nusantara civilization 4, no. 02 (2020): 2952.

Susanto, Edi, dan Karimullah Karimullah. "Islam Nusantara: Islam Khas dan Akomodatif terhadap Budaya Lokal.” Al-Ulum 16, no. 1 (2016): 56-80.

Syafrizal, Achmad. "Sejarah Islam Nusantara.” Islamuna: Jurnal Studi Islam 2, no. 2 
YAQZHAN | Volume 07, Nomor 02, Desember 2021

(2015): 235-53.

Wahid, Abdurrahman. Islam Kosmopolitan; Nilai-nilai Indonesia dan Transformasi Kebudayaan. Jakarta: The Wahid Institute Seeding Plural and Peaceful Islam, 2007. Zed, Mestika. Metode Penelitian Kepustakaan. Jakarta: Yayasan Obor Indonesia, 2008. Zuhdi, Muhammad Harfin. "Islam Wetu Telu [Dialektika Hukum Islam dengan Tradisi Lokal].” Istinbath: Jurnal Hukum Islam IAIN Mataram 13, no. 2 (2014): 41814. 